\title{
Progress and challenges in animal handling and slaughter in the U.S. is
}

\author{
Temple Grandin*
}

Department of Animal Sciences, Colorado State University, Fort Collins, CO 80523, USA

Available online 21 June 2006

\begin{abstract}
Both well-designed equipment and trained employees are required to maintain a high standard of animal welfare during slaughter. When McDonald's Corporation started auditing U.S. beef and pork slaughter plants in 1999, there were great improvements in handling and stunning. They used a numerical objective scoring system. It contained five basic measurements: (1) the percentage of animals stunned on the first attempt, (2) percentage rendered insensible prior to hoisting, (3) percentage vocalizing during handling and stunning, (4) percentage that fall down and (5) percentage moved with an electric goad. Each variable was scored on a simple yes/no basis. Baseline data was collected prior to the McDonald's audits in 1996. The most striking improvements were in beef. The average effective first shot stunning score was $89.5 \%$ in 1996 , $96.2 \%$ in 1999 and $98.6 \% 5$ years later in 2003 . The average percentage of cattle vocalizing during stunning and handling was $10 \%$ in $1996,2.4 \%$ in 1999 and $2.0 \%$ in 2003 . A total of 50 plants were audited. Most plants were able to greatly improve welfare by improving stunner maintenance; installing non-slip floor gratings in stun boxes and better training. They also had to make simple, low cost changes to eliminate distractions that cause animals to balk and refuse to move. The most common ways to improve animal movement were: (1) install a lamp on a dark race entrance, (2) move ceiling lamps to eliminate sparkling reflections, (3) muffle air hissing, (4) install shields and solid sides on races to prevent animals from seeing moving people up ahead and (5) eliminate air drafts that blow in the faces of approaching animals. A major remaining problem area is in plants that are not in a program of yearly audits by restaurants. Serious animal abuse has occurred in some of these non-audited plants.

(C) 2006 Elsevier B.V. All rights reserved.
\end{abstract}

Keywords: Cattle; Pigs; Slaughter; Welfare; Handling; Stunning

This paper is part of the special issue entitled Sentience in Animals, Guest Edited by Dr. John Webster.

* Tel.: +1 970229 0703/221 8046/491 1442 (O); fax: +1 9704915326.

0168-1591/\$ - see front matter (C) 2006 Elsevier B.V. All rights reserved.

doi:10.1016/j.applanim.2006.04.016 


\section{Introduction}

This paper reviews over 30 years of work designing handling facilities in pork and beef slaughter plants. Half of the cattle in the U.S. and Canada are handled in a restrainer system designed by myself, and approximately $35 \%$ of all the pigs and cattle in the U.S. are handled in my race and stockyard designs (Grandin, 1980, 1990, 2000a,b,c, 2003). I have also trained employees in over 200 slaughter plants in the U.S., Europe, Canada, Australia, and South America. When I first started designing equipment in the mid 1970s, I used to believe that there was an engineering solution to all of the animal handling and stunning problems. If the perfect system could be built, then high standards of animal welfare would be maintained. I quickly learned that well-designed equipment makes it easier to handle and stun animals with a minimum of excitement and distress, but it is useless unless it is operated correctly. One of my biggest frustrations was that in about half of the plants, the people failed to operate the new equipment correctly. They also did a poor job of maintaining the facilities. Both good equipment and good management are required to keep welfare at an acceptable level. Too often people will buy the new facility but may not provide enough management supervision to use it properly.

\section{Are animals afraid of being slaughtered?}

Early in my career I wanted to find out if cattle knew they were going to get slaughtered. On many different days, I watched cattle moving through the races at a slaughter plant. I then went out to a feedlot to watch cattle being moved through a race for vaccinations. In both of these places, the cattle were moved quietly and an electric goad was only used on animals that balked or backed up. I observed that they behaved the same way in both places. If they knew they were going to die, they should have been more agitated in the slaughter plan. The cattle were more concerned about a little moving, dangling chain. At one slaughter plant they refused to enter the race after a white plastic water bottle had accidentally fallen on the floor at the race entrance.

\section{Recognizing the importance of behavior}

It is often difficult to get people who work with animals to fully appreciate that the use of behavioral principles, both in equipment design and by people handling animals is usually more effective than force. If an animal backs up and refuses to enter a race or restrainer, one should figure out why it is balking instead of resorting to an electric goad. The most common causes of balking are shiny reflections on metal or water, dangling chains, seeing people up ahead or air blowing into the faces of approaching animals (Grandin, 1996). Animals are also afraid to enter a dark place. In many cases, adding a light at either the race or restrainer entrance will facilitate animal movement. Both pigs and cattle have a tendency to move from a darker place towards a brighter place (Van Putten and Elshoff, 1978; Grandin, 1982, 2002; Tanida et al., 1996). Simple changes such as adding a light to illuminate a dark entrance, or moving a lamp to eliminate a reflection will stop balking. When the distractions that attract the animal's attention are removed from the facility, the animals will walk quietly into the stunning area. Movement of both cattle and pigs will also be improved if solid sides are installed on races to prevent the animals from seeing people and moving equipment outside the race.

One of the prime objectives in the management of any abattoir is to prevent bad from becoming normal. This requires training in the behavioral principles of cattle and pig handling. Handlers can be shown how to move animals quietly by positioning themselves in the correct 
position (Grandin, 1980, 1987, 2000a,b,c). Some of the handlers always used behavioral principles for moving animals, but others would slowly revert back to old rough ways. In some cases, they did not realize that the electric goad was gradually being used more and more. I call this "bad becoming normal" and have observed this problem over and over again in many different places. To prevent this from happening, management must conduct regular measurements of handling. "Bad becoming normal" can be prevented by keeping track of the percentage of animals moved with the electric goad and the percentage that fall down. Numerical scoring enables management to determine whether their performance is improving or becoming worse. Guidelines that contain vague terms like sufficient, adequate or properly are rarely effective. What one person may consider proper handling, another person may think is abusive. Guidelines need to be specific. An example of a clearly worded guideline would be "All cattle should be moved quietly at a walk or trot".

\section{Development of an objective numerical scoring system for animal handling and stunning}

The U.S. Department of Agriculture hired me in 1996 to survey a total of 24 federally inspected beef, veal, work and sheep slaughter plants. They instructed me to develop a more objective method to evaluate stunning and handling practices than observing and giving my opinion. The end result was a simple but effective scoring system where 100 cattle or pigs are scored on five variables (Grandin, 1998a,b). Each variable is scored on a yes/no basis for each. The variables are:

- Percentage of animals stunned correctly on the first attempt.

- Percentage rendered completely insensible prior to hoisting - must be $100 \%$ to pass the audit.

- Percentage that vocalize (moo, bellow, or squeal) during movement up the race and in the stunning box. Each animal is scored as either silent or as a vocalizer. Vocalizations in the lairage are not counted.

- Percentage that slip and fall down during unloading, driving and restraint.

- Percentage moved with an electric goad.

This system was modeled after the HACCP programs that are used to monitor food safety. HACCP stands for hazard analysis at critical control points. The principle is to use a small number of measurable critical control points that measure many different problems. For example, a poor stunning score could be caused by a lack of stunner maintenance, untrained employees, damp cartridges or agitated animals. A high vocalization score could be caused by excessive electric goad use, missed stuns, slipping in the stun box, or too much pressure or pinching from a head holding device (Grandin, 1998b). Excessive electric goad use can be caused by either a lack of employee training or animals constantly balking and backing up.

Previous research clearly indicates that vocalizations during handling or surgical procedures are an indicator of stress (Weary et al., 1998; White et al., 1995; Dunn, 1990) in pigs. Warriss et al. (1994) reported that the sound level of pigs vocalizing in a slaughter plant was positively correlated with higher cortisol levels. Grandin (1998b) observed a total of 1125 cattle while they were in the single file race or stunning box in six commercial slaughter plants. A total of 112 cattle vocalized during handling and stunning. All but two were associated with an observable aversive event such as electric goads, slipping on the stun box floor, missed captive bolt stuns or excessive pressure applied to the animal by a restraining device (Grandin, 1998b). Further study indicated that problems with equipment could be identified and fixed by comparing before and 
after vocalization scores (Grandin, 2002). In one beef plant, an $8 \%$ vocalization score dropped to $0 \%$ after a light was installed on a dark restrainer entrance. Electric goad use could be reduced because the cattle balked less. In another plant, excessive pressure from a head restraint device caused $23 \%$ of the cattle to vocalize. After the pressure was reduced, the percentage that vocalized was reduced to $0 \%$.

Vocalization scoring is more difficult in pigs because it is often impossible to count the individual pigs that are squealing. In plants with very good handling where individual squealing pigs can be identified, they can be scored the same way as cattle. In large plants a sound meter can be used to monitor pig squealing. Another method for measuring pig vocalization is to score the percentage of stunning cycles where the entire room was quiet.

\section{Results of the USDA survey and industry voluntary standards}

Ten beef plants were surveyed and only three out of the 10 plants were able to achieve the voluntary American Meat Institute standard of $95 \%$ of the cattle rendered insensible with one shot. Cattle that were missed were immediately restunned. In four plants $(40 \%)$ a lack of maintenance of the captive bolt stunner was the cause of poor stunning.

Out of the eight pork plants, six (75\%) achieved the voluntary industry standard of $99 \%$ correct electrode placement. The plants were also scored for "hot wanding" where the tongs are energized prior to placement. This will cause pigs to squeal. Five out of the eight plants (62\%) achieved the voluntary standard of $1 \%$ hot wanded. All pigs and cattle were rendered completely insensible prior to bleeding.

The U.S. voluntary standard for pigs and cattle falling during stunning and handling is $1 \%$. Falling was either a serious problem in a plant or it was $0 \%$. Since the scoring system was under development, falling scores were obtained in only five cattle plants. In one plant, $8 \%$ of the cattle fell and the rest were $0 \%$. The voluntary industry standard for electric goad use for both cattle and pigs is that $75 \%$ or more of the animals must be moved with no electric goad. Data were collected in four beef and four pork plants that had well-trained handlers who only used the electric goad on animals that refused to move. This was done to determine the industry standard for electric goad use. The scores for beef were $5 \%, 10 \%, 10 \%$ and $64 \%$ and for pigs $6 \%, 19 \%, 15 \%$, and $28 \%$. Vocalization data were collected in six beef plants. The scores ranged from $0 \%$ to $35 \%$. The voluntary industry standard for cattle vocalization is $3 \%$. If a plant uses a head holder for either stunning or religious slaughter, the acceptable percentage is $5 \%$.

\section{Restaurant audits improve animal welfare in slaughter plants}

In 1999, McDonald's Corporation started auditing beef and pork slaughter plants. To pass, a plant had to be in the acceptable range on all five of the American Meat Institute objectively scored critical control points. I worked with the McDonald's food safety auditors to train them how to score 100 cattle or pigs in each plant on the five critical control points. The McDonald's, Wendy's International, and American Meat Institute audits also have five acts of abuse that will result in an automatic audit failure. They are (1) sticking a prod or other object in a sensitive part of the animal, (2) dragging non-ambulatory animals, (3) driving other animals over the top of a downed animal on purpose, (4) slamming gates on purpose on an animal and (5) beating an animal. These audits brought about more improvement than I had seen during the previous 25 years of my career. I visited 26 plants in 1999 along with the McDonald's food safety auditors. At first, the industry did not take the audits seriously. After a very large plant was removed from the 
Table 1

Comparison of cattle stunning performance before and after restaurant welfare audits

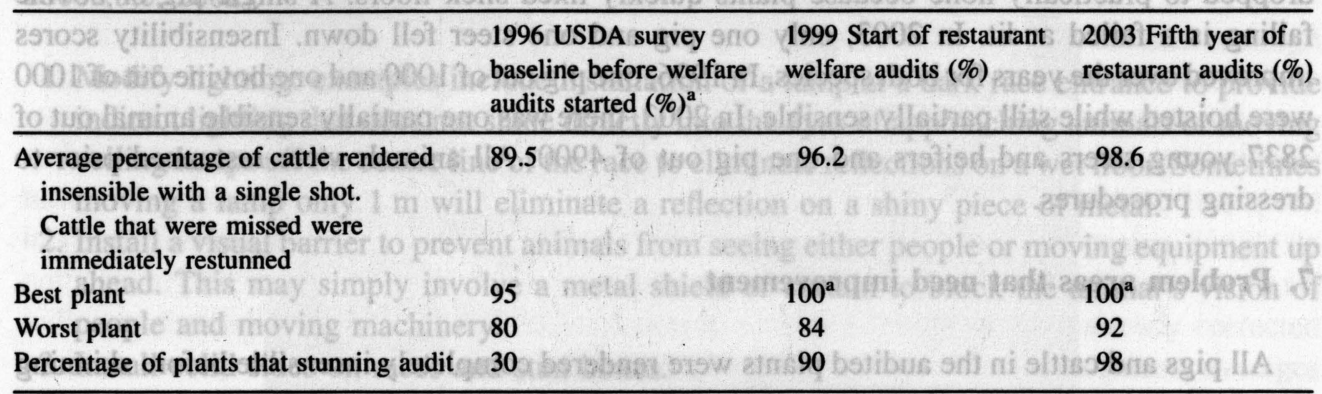

$1996-N=10$ plants; $1999-N=41$ plants; $2003-N=50$ plants.

a This score is based upon a 100 cattle audit. When internal plant data is collected, the very best plant was able to maintain an average stunning score of over $\mathbf{9 9 . 5 \%}$. Absolute perfection is impossible.

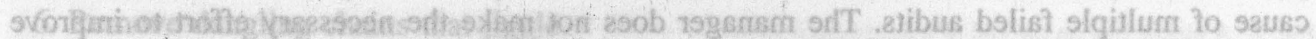

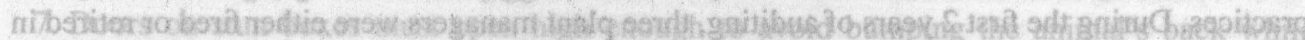

approved supplier list, plant mangers became serious about improving animal welfare. The audits motivated the industry to do a better job of supervising employees and maintaining equipment.

Tables 1 and 2 show comparisons between the 1996 USDA survey scores and the 1999 and 2003 restaurant audits. Cattle plants had the most striking improvements. In 1996, only three plants out of 10 passed the stunning audit and stunned $95 \%$ or more of the cattle with one shot. For a 5-year period from 1999 to 2003, $90 \%$ or more of the plants passed. All animals that were missed by the first shot were restunned prior to bleeding. Vocalization scores also showed impressive improvements (Table 2). For electric goad use, the percentage of plants that passed by moving $75 \%$ or more of the cattle with no electric prod was $76 \%$ in 1999 and $90 \%$ in 2003 . By 2003 most plants had fixed floors to prevent falls. Out of 50 beef plants and 24 pork plants, only two animals fell.

Improvements in stunning and handling pigs were less compared to beef. The pork industry was doing a better job with electric stunning compared to captive bolt stunning of beef. The percentage of pork plants that passed with $99 \%$ correct placement were $79 \%$ in 1999 , and in $2003,91 \%$ passed. The percentage of plants that passed the audit for electric prod use were 1999

Table 2

Comparison of cattle vocalization scores before and after restaurant audits

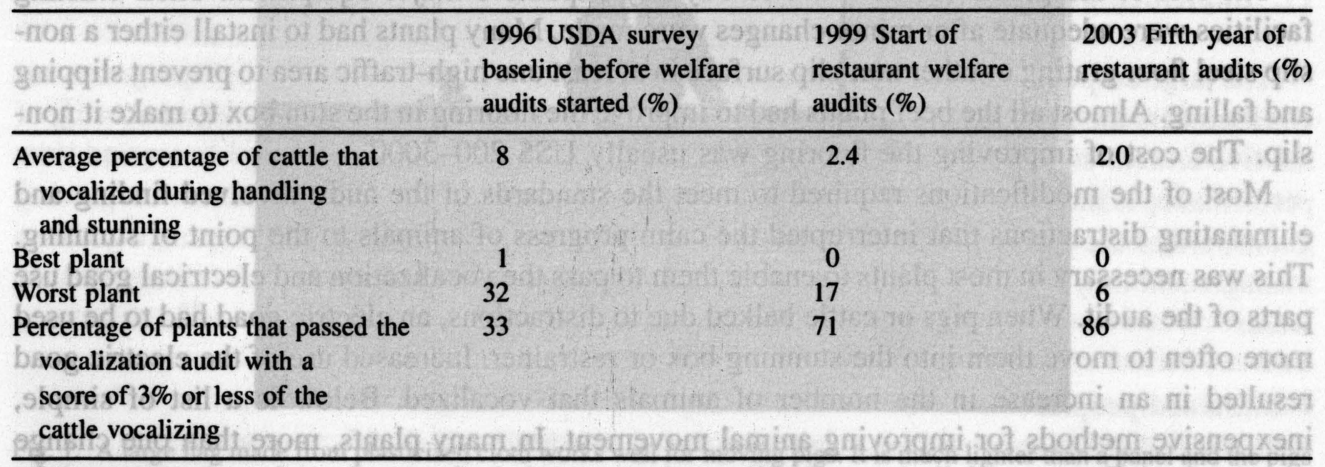

$1996-N=6$ plants; $1999-N=41$ plants; $2003-N=50$ plants. 
data not collected, 2000, 79\% passed, and 2003, 79\% passed. Problems with animals falling dropped to practically none because plants quickly fixed slick floors. A single pig or bovine falling is a failed audit. In 2003 , only one pig and one steer fell down. Insensibility scores improved over the years for both species. In 1996, one pig out of 1000 and one bovine out of 1000 were hoisted while still partially sensible. In 2003, there was one partially sensible animal out of 2837 young steers and heifers and one pig out of 4900 . All animals were restunned prior to dressing procedures.

\section{Problem areas that need improvement}

All pigs and cattle in the audited plants were rendered completely insensible before skinning or any other dressing procedures were started. Stunning bulls reliably with captive bolt is still a problem area. There have been great improvements due to the audits in most plants, but a few plants continue to fail audits. I have observed that a manager with a poor attitude is often the cause of multiple failed audits. The manager does not make the necessary effort to improve practices. During the first 2 years of auditing, three plant managers were either fired or retired in large corporate plants. Some of the remaining bad problems are most likely to occur in smaller plants where the manager is a family member and he/she cannot be easily removed. I have observed that family owned independent plants are either really good or very bad.

One of the big concerns is that a two-tier industry is forming. Plants that are audited by restaurants or supermarkets will maintain decent standards but plants that are outside of the auditing system may have more problems. In the U.S., some really atrocious abuses occurred in pork and beef plants that were not audited by a restaurant or supermarket.

\section{Changes plants had to make to pass the audits}

Most plants subject to audit were able to meet the required standards after making many small changes that were not expensive. Out of 50 beef plants and 24 pork plants, only two plants had to purchase major pieces of equipment to pass the audits. One beef plant had to install a new curved race and restrainer system. For new construction, curved races with solid sides are strongly recommended for cattle because cattle tend to balk less in a curved race.

A pork plant had to buy an additional $\mathrm{CO}_{2}$ machine because their unit was totally overloaded. To keep up with production, they were forcing pigs to jump onto the backs of other pigs. They used an electric goad to force three pigs in gondolas designed for two.

The rest of the plants did not have to buy any expensive major equipment. Their existing facilities were adequate after minor changes were made. Many plants had to install either a nonslip steel floor grating or other non-slip surface in at least one high-traffic area to prevent slipping and falling. Almost all the beef plants had to improve the flooring in the stun box to make it nonslip. The cost of improving the flooring was usually US\$200-3000.

Most of the modifications required to meet the standards of the audit involved finding and eliminating distractions that interrupted the calm progress of animals to the point of stunning. This was necessary in most plants to enable them to pass the vocalization and electrical goad use parts of the audit. When pigs or cattle balked due to distractions, an electric goad had to be used more often to move them into the stunning box or restrainer. Increased use of the electric goad resulted in an increase in the number of animals that vocalized. Below is a list of simple, inexpensive methods for improving animal movement. In many plants, more than one change was required. To successfully locate the distractions, people had to get down into the race and get 
an animal's eye view. These are discussed in greater detail elsewhere (Grandin, 1992, 1994, 1996, 2000a,b,c, 2002).

1. Modify lighting: examples include installation of a lamp at a dark race entrance to provide indirect lighting that does not shine directly into the eyes of approaching animals or moving ceiling lamps off the centre line of the race to eliminate reflections on a wet floor. Sometimes moving a lamp only $1 \mathrm{~m}$ will eliminate a reflection on a shiny piece of metal.

2. Install a visual barrier to prevent animals from seeing either people or moving equipment up ahead. This may simply involve a metal shield or curtain to block the animal's vision of people and moving machinery.

3. Install solid sides on races and stun boxes.

4. Cut a small window in the front of a beef stun box so it does not look like a dead-end.

5. Change the ventilation system to prevent air from blowing into the faces of the approaching animals.

6. Remove dangling chains that jiggle.

7. Doors on stun boxes must open high enough to avoid bumping the animal's back while entering.

8. Hold-down bars on races or restrainers should not touch the animal's back.

9. Install a false floor under a conveyor restrainer so that the animal does not balk at the visual cliff effect.

10. Install speed controls on hydraulic or pneumatic cylinders to eliminate sudden jerking movement that scares animals.

11. Silence hissing air with mufflers.

12. Reduce metal clanging noise.

13. Avoid excessive pressure on head holder devices and other restraint apparatus.

\section{New driving aids}

Plant employees became very creative in designing new driving aids to replace electric goads. Many types of flags were developed (Fig. 1). One of the most common and very effective

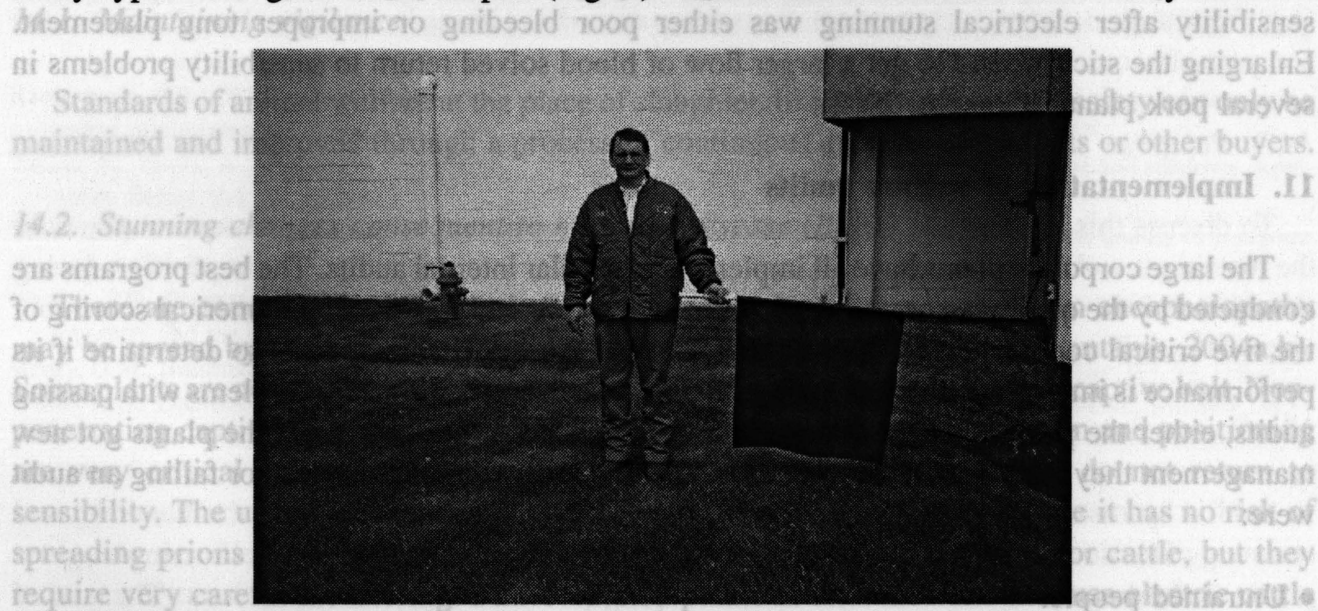

Fig. 1. A large flag made from plasticized cloth works well for moving pigs. It is much lighter than a panel and the pigs move away because they cannot see through it. 


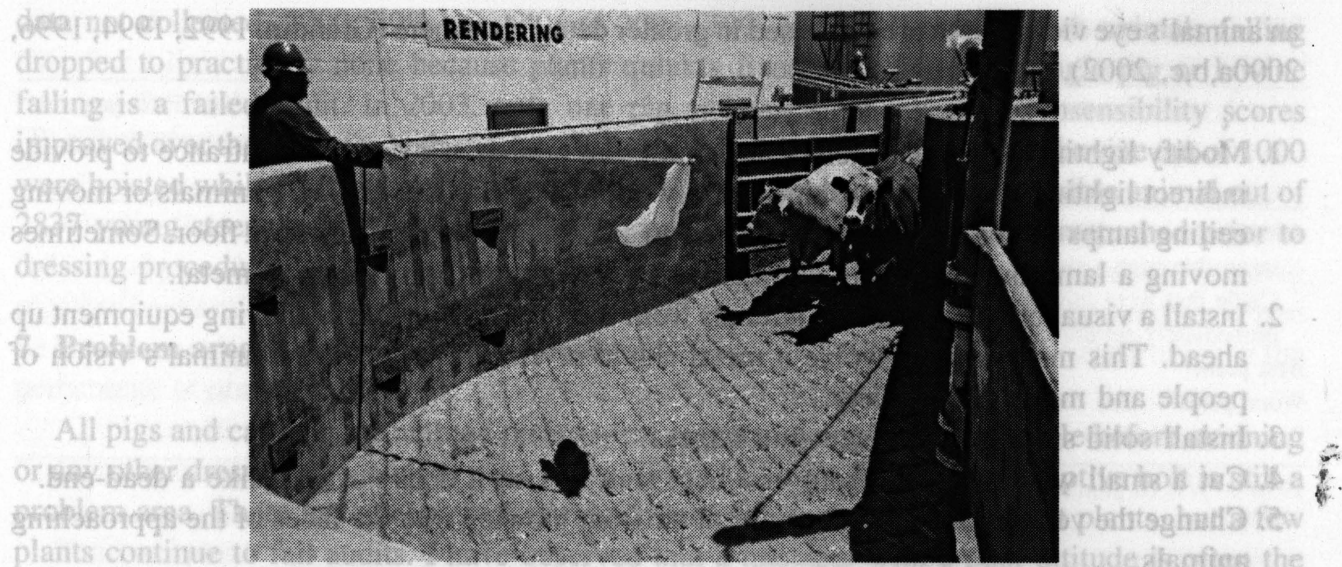

Fig. 2. A plastic bag on the end of a lightweight stick can be used to turn and direct cattle into the race. Calm cattle will turn when the bag is moved alongside their head.

alternative driving aid was a plastic bag or plastic streamers taped to the end of a stick (Fig. 2). Several plants developed a vibrating prod for moving cattle. The employees were trained to use the non-electrified aid as their primary driving tool and resort to the electric goad only if an animal refused to move. One problem was that some employees wanted to get a good electric goad score so they beat a stubborn animal when they should have used the electric goad. This is why the American Meat Institute Guidelines allow $25 \%$ of the animals to be electrically goaded.

\section{Stunning and bleeding improvements}

Poor maintenance of captive bolt stunners was a major reason for failed stunning audits (Grandin, 2002). Many plants now have a documented stunner maintenance program. The equipment companies responded by developing test stands to measure bolt velocity. Sufficient bolt velocity is essential for effective stunning (Gregory, 1998). In pigs, a major cause of return to sensibility after electrical stunning was either poor bleeding or improper tong placement. Enlarging the stick wound to get a larger flow of blood solved return to sensibility problems in several pork plants (Grandin, 2002).

\section{Implementation of welfare audits}

The large corporate plants have all implemented regular internal audits. The best programs are conducted by the quality assurance staff. Both shifts are scored weekly with numerical scoring of the five critical control points. The use of numerical scoring enables a plant to determine if its performance is improving or deteriorating. In three plants that had chronic problems with passing audits, either the plant manager or superintendent had to be replaced. After the plants got new management they passed all their welfare audits. The most common reasons for failing an audit were:

- Untrained people.

- Physical distractions that cause animals to stop moving.

- Major equipment problems such as overloaded or poorly designed equipment. 


\section{Effect of line speed on welfare}

Another contentious issue is the plant's production line speed. Many people assume that high line speeds automatically mean bad welfare. A plant with a high line speed can achieve excellent numerical scores provided it is designed and staffed correctly for its speed. Line speed will cause problems when a line is either understaffed or the equipment is overloaded. The equipment must have sufficient capacity for the line speed. Equipment that is too small for a particular line speed has been a major problem with $\mathrm{CO}_{2}$ stunning. Since the equipment is very expensive, people do not want to purchase a larger machine. Data collected on captive bolt stunning in over 50 plants indicated that line speed had no effect on stunning scores. These plants had already corrected problem so they could remain in the improved supplier list. The first shot stunning score averages were: under 50 cattle per hour $96.2 \%, 51-100$ per hour $98.9 \%, 101-200$ per hour $97.4 \%$ and over 200 per hour $96.7 \%$. Cattle that were used were immediately restunned.

\section{Economic drivers of progress}

When McDonald's Corporation and Wendy's International used their tremendous purchasing power to improve animal welfare, the effects were dramatic. McDonalds purchased beef from about $90 \%$ of the large and medium sized plants in the U.S. When a large plant is threatened with losing a million dollars worth of business they pay attention. During my career I have observed that economic incentives are very effective. If people are rewarded financially for reducing bruises or other damage they work hard to minimize bruises. If a truck driver gets an insurance payment for every dead pig, he will have no incentive to take better care of the pigs. Today I have been spending less time on doing design work and more time working with major buyers of meat. Helping these buyers to develop effective practical programs will bring about the most progress.

\section{Challenges ahead}

In this final section I highlight some of the most important challenges that lie ahead.

\subsection{Maintaining vigilance}

Standards of animal welfare at the place of slaughter, like standards of food safety can only be maintained and improved through a process of continuous audit by restaurants or other buyers.

\subsection{Stunning changes consequent to mad cow disease (BSE)}

There are concerns that prions, the infective agent for bovine spongiform encephalopathy may be spread by penetrating captive bolt stunning (Anil et al., 1999; Ramantanis, 2004a,b). Some plants are now using non-penetrating captive bolt instead of penetrating captive bolt. Nonpenetrating captive bolt reduces BSE risks (Bradley and Budkha, 2001). Aim and positioning are very critical and careful monitoring is essential to insure that cattle do not return to sensibility. The use of electrical stunning of cattle may also increase because it has no risk of spreading prions from the brain. Electrical stunning systems are effective for cattle, but they require very careful monitoring. I have audited plants in New Zealand that use electric cattle stunning and they were able to pass the audit. I also observed some very poor electric stunning in South America. 


\subsection{Plants with chronic problems}

Tables 1 and 2 show that there are still plants that have with chronic problems and do the bare minimum to pass their audits. Most of these problems are due to poor management. These plants should receive unannounced audits. There are some really atrocious plants but most of these have never been a McDonald's or Wendy's supplier. When a new plant gets its first audit it will often fail because they do not know what to expect. They should be given a second chance to pass.

\subsection{Auditor training}

I have trained over 50 auditors to score plants with the numerical scoring system. I have learned that criteria need to be simple or it is impossible to get consistent results between different auditors. One advantage of the numerical score system is that it is easy to learn. Each animal is scored on a yes/no basis for each critical control point.

\subsection{Education in farm animal welfare}

I have observed that there are not enough young students who are prepared to work on farm animal welfare out in the field. Part of the lack of interest may be due to the fact that young students have less practical experience with farm animals at a young age. Veterinary schools in the U.S. are having a difficult time finding enough students who want to work with farm animals. Programs need to be developed to interest students in working with farm animals.

\subsection{Ensuring uniformity of standards}

For the last 6 years I have worked to keep the standards uniform so that Wendy's, McDonalds and other companies use the same standard. The industry will be more resistant and will have a harder time complying if different companies have different standards. Standardization of welfare at slaughter is easier than standardization of welfare on the farm standards because slaughtering is the same, however, the animals may have been managed throughout their lives (e.g. free-range or intensively reared). Some very disturbing abuse has occurred in plants that are not part of a customer audit program.

\subsection{Religious slaughter}

To discuss this issue fully is beyond the scope of this paper. There are some kosher plants in the restaurant auditing system. They are required to hold the animal in an upright position during shechita and the plant must be able to pass the audit for electric goad use, falling down and vocalization. They fail if more than $5 \%$ of the cattle vocalize.

\section{Conclusions}

Audits by restaurant companies have brought about big improvements in the handling and stunning of cattle and pigs. One of the most effective ways to improve animal welfare in slaughter plants is for large corporations to use their buying power to improve conditions. The use of numerical objective scoring was effective because it was easy to train the auditors and the plant managers knew exactly what was expected. Having hard numbers as records of performance 
helps prevent performance from slipping. Some people have criticized the auditing system because when performance is measured with numbers, perfect scores are impossible. However, the records show that the use of numerical scoring maintains animal welfare at a higher standard than the use of more subjective methods.

\section{References}

Anil, M.H., Lowe, S., Williams, S., Shand, A., McKinstry, J.L., Waterman-pearson, Seghatchian, A., Harbour, D.A., 1999. Potential contamination of beef carcasses with brain tissue at slaughter. Vet. Rec. 145, 450-462.

Bradley, R., Budkha, H., 2001. Scientific Report on stunning and BSE Risks, European Commission, Health and Consumer Protection, Directorate General, Brussels, Belgium.

Dunn, C.S., 1990. Stress reactions of cattle undergoing ritual slaughter using two methods of restraint. Vet. Rec. 126, 522525.

Grandin, T., 1980. Observations of cattle behavior applied to the design of cattle handling facilities. Appl. Anim. Ethol. 6, 19-31.

Grandin, T., 1982. Pig behavior studies applied to slaughter plant design. Appl. Anim. Ethol. 9, 141-151.

Grandin, T., 1987. Animal handling. Vet. Clin. N. Am.: Food Anim. Pract. 3, 323-338.

Grandin, T., 1990. Design of loading and holding pens. Appl. Anim. Behav. Sci. 28, 187-201.

Grandin, T., 1992. Observations of cattle restraint devices for stunning and slaughtering. Anim. Welfare 1, 85-91.

Grandin, T., 1994. Euthanasia and slaughter of livestock. J. Am. Vet. Med Assoc. 204, 1354-1360.

Grandin, T., 1996. Factors that impede animal movement in slaughter plants. J. Am. Vet. Med. Assoc. $209,757-759$.

Grandin, T., 1998a. Objective scoring of animal handling and stunning practices in slaughter plants. J. Am. Vet. Med. Assoc. 212, 36-39.

Grandin, T., 1998b. The feasibility of using vocalization scoring as an indication of poor welfare during cattle slaughter. Appl. Anim. Behav. Sci. 56, 121-128.

Grandin, T., 2000a. Effect of animal welfare audits of slaughter plants by a major fast food company on animal handling and stunning practices. J. Am. Vet. Med. Assoc. 216, 848-851.

Grandin, T., 2000b. Livestock Handling and Transport. CAB International, Wallingford, Oxon, UK.

Grandin, T., 2000c. Return to sensibility problems after penetrating captive bolt stunning of cattle in commercial slaughter plants. J. Am. Vet. Med. Assoc. 221, 1258-1261.

Grandin, T., 2002. Cattle vocalizations are associated with handling and equipment problems at beef slaughter plants. Appl. Anim. Behav. Sci. 71, 191-201.

Grandin, T., 2003. Transferring results of behavioral research to industry to improve animal welfare on the farm, ranch and the slaughter plant. Appl. Anim. Behav. Sci. 81, 215-228.

Gregory, N.G., 1998. Animal Welfare and Meat Science. CAB International, Wallingford, Oxon, UK.

Ramantanis, S.B., 2004a. Cattle slaughtering and BSE risks. Part I. Potential dissemination of CNS tissue during slaughtering. Vet. Bull. 74 (3), 1N-13N.

Ramantanis, S.B., 2004b. Cattle slaughtering and BSE risks. Part II. Alternative and/or additional means of preventing and/or minimizing the dispersal of CNS material during slaughter. Vet. Bull. 74 (3), $15 \mathrm{~N}-26 \mathrm{~N}$.

Tanida, H., Miura, A., Tanaka, T., Yoshimoto, T., 1996. Behavioral responses of piglets to darkness and shadows. Appl. Anim. Behav. Sci. 49, 173-813.

Van Putten, G., Elshoff, G., 1978. Observations on the effect of transport on the well being and lean quality of slaughter pigs. Anim. Regul. Stud. 1, 247-271.

Warriss, P.D., Brown, S.N., Adams, S.J.M., 1994. Relationship between subjective and objective assessment of stress at slaughter and meat quality in pigs. Meat Sci. 38, 329-340.

Weary, D.M., Braithwaite, L.A., Fraser, D., 1998. Vocal response to pain in piglets. Appl. Anim. Behav. Sci. 56, $168-172$.

White, R.G., DeShazer, J.A., Treassler, C.J., Borcher, G.M., Davey, S., Warninge, A., Parkhurst, A.M., Milanuk, M.J., Clems, E.T., 1995. Vocalizations and physiological response of pigs during castration with and without anesthetic. J. Anim. Sci. 73, 381-386. 